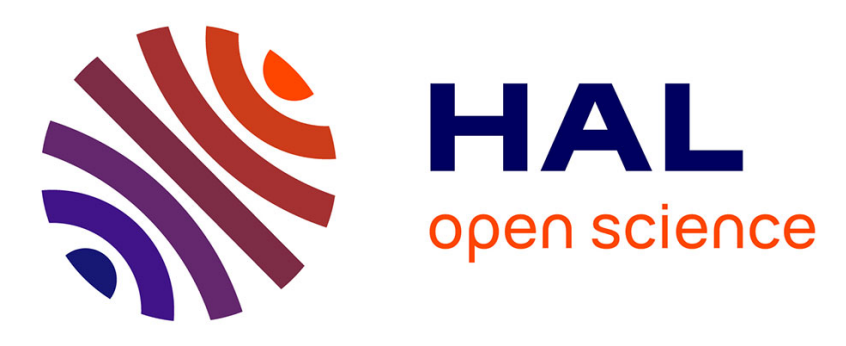

\title{
Glycan-functionalized diamond nanoparticles as potent E. coli anti-adhesives
}

Alexandre Barras, Fernando Ariel Martin, Omprakash Bande, Jean-Sébastien Baumann, Jean-Marc Ghigo, Rabah Boukherroub, Christophe Beloin, Aloysius Siriwardena, Sabine Szunerits

\section{To cite this version:}

Alexandre Barras, Fernando Ariel Martin, Omprakash Bande, Jean-Sébastien Baumann, JeanMarc Ghigo, et al.. Glycan-functionalized diamond nanoparticles as potent E. coli anti-adhesives. Nanoscale, 2013, 5 (6), pp.2307-2316. 10.1039/c3nr33826f . pasteur-01385429

\section{HAL Id: pasteur-01385429}

https://hal-pasteur.archives-ouvertes.fr/pasteur-01385429

Submitted on 5 May 2021

HAL is a multi-disciplinary open access archive for the deposit and dissemination of scientific research documents, whether they are published or not. The documents may come from teaching and research institutions in France or abroad, or from public or private research centers.
L'archive ouverte pluridisciplinaire HAL, est destinée au dépôt et à la diffusion de documents scientifiques de niveau recherche, publiés ou non, émanant des établissements d'enseignement et de recherche français ou étrangers, des laboratoires publics ou privés.

\section{(ㅇ)(1) $\$$}

Distributed under a Creative Commons Attribution - NonCommercial| 4.0 International 


\section{TOC image}
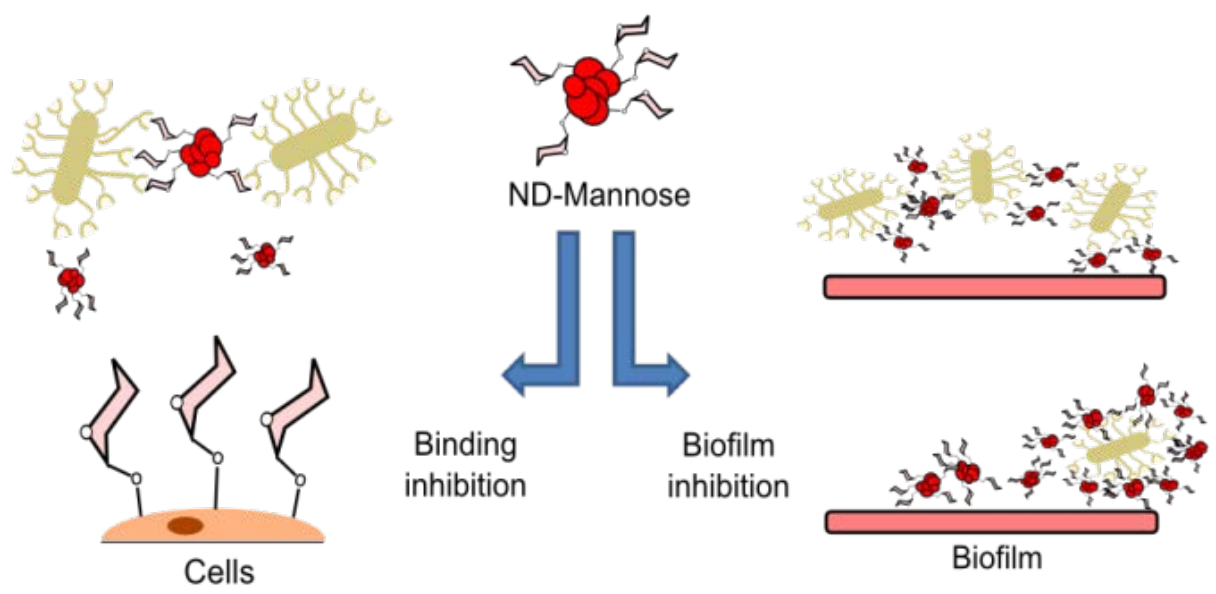

Glyco-nanodiamonds have been studied as highly specific anti-adhesives for $E$. coli adhesion to biotic surfaces. 


\section{Glycan-functionalized diamond nanoparticles as potent $E$. coli anti-adhesives}

Alexandre Barras, ${ }^{\mathrm{a}, \#}$ Fernando Ariel Martin, ${ }^{\mathrm{b}, \text { \# } 1}$ Omprakash Bande, ${ }^{\mathrm{c}, 2}$ Jean-Sébastien Baumann, ${ }^{\mathrm{c}}$ Jean-Marc Ghigo, ${ }^{\mathrm{b}}$ Rabah Boukherroub, ${ }^{\mathrm{a}}$ Christophe Beloin, ${ }^{\mathrm{b},{ }^{*}}$ Aloysius Siriwardena, ${ }^{\mathrm{c},{ }^{*}}$ Sabine Szunerits ${ }^{\mathrm{a},{ }^{*}}$

${ }^{a}$ Institut de Recherche Interdisciplinaire (IRI, USR CNRS 3078), Université Lille 1, Parc de la Haute Borne, 50 Avenue de Halley, BP 70478, 59658 Villeneuve d'Ascq, France.

${ }^{b}$ Institut Pasteur, Unité de Génétique des Biofilms, 25 rue du Dr. Roux, 75724 Paris cedex 15, France.

${ }^{c}$ Laboratoire des Glucides (FRE 3517 CNRS), Université de Picardie Jules Vernes, 33 rue saint Leu, 80039 Amiens, France.

Keywords: diamond nanoparticles, "click" chemistry, mannose, adhesion interference, $E$. coli, FimH, biofilm

\# equivalent contribution

${ }^{1}$ present address: INSERM U1001, Université Paris Descartes, Faculté de Médecine Necker, 156 rue de Vaugirard 75015 Paris, France

2 present address: Rega Institute for Medical Research, Laboratory for Medicinal Chemistry, Minderbroedersstraat 10, B-3000 Leuven, Belgium

* to whom correspondence should be sent: cbeloin@pasteur.fr; aloysius.siriwardena@upicardie.fr; Sabine.Szunerits@iri.univ-lille1.fr 


\begin{abstract}
:
Bacterial attachment and subsequent biofilm formation on biotic surfaces or medical devices is an increasing source of infections in clinical settings. A large proportion of these biofilmrelated infections are caused by Escherichia coli, a major nosocomial pathogen, in which the major adhesion factor is the FimH adhesin located at the tip of type 1 fimbriae. Inhibiting FimH-mediated adhesion has been identified as an efficient antibiotic-alternative strategy to potentially reduce $E$. coli-related infections. In this article we demonstrate, that nanodiamond particles, covently modified with mannose moieties by a "click" chemistry approach are able to efficiently inhibit $E$. coli type 1 fimbriae-mediated adhesion to eukaryotic cells with relative inhibitory potency (RIP) of as high as 9259 (bladder cell adhesion assay), which is unprecedented when compared with RIP values previously reported for alternate multivalent mannose-functionalized nanostructures designed to inhibit E. coli adhesion. Also remarkable is that these novel mannose-modified NDs reduce E. coli biofilm formation, a property previously not observed for multivalent glyco-nanoparticles and rarely demonstrated for other multivalent or monovalent mannose glycans. This work sets the stage for the further evaluation of these novel NDs as an anti-adhesive therapeutic strategy against $E$. coli-derived infections.
\end{abstract}




\section{INTRODUCTION}

The initial interaction between pathogenic bacteria and host cells is one of the critical steps leading to host colonization. These first adhesion events allow host-pathogen recognition and prevent bacteria from being washed out by the host and are generally mediated by specific proteins called adhesins. In Escherichia coli (E. coli), one of the best-characterized adhesins and considered one of the major virulence factors of E. coli is FimH. FimH is located at the tip of type 1 fimbriae, filamentous tubular structures each of 0.2-2.0 $\mu \mathrm{m}$ in length and 5-7 nm in diameter that are distributed over the entire surface of the bacterium. ${ }^{1}$ Known to promote biofilm formation on various plastic or glass abiotic surfaces ${ }^{2-5} \mathrm{FimH}$ also mediates binding of $E$. coli to a variety of eukaryotic cells from multiple tissues. ${ }^{6-11}$ In uropathogenic $E$. coli (the major etiological agent of urinary tract infections) FimH contribute specifically to bladder colonization through binding to terminal $\alpha$-D-mannosyl units present on glycoproteins such as uroplakins. ${ }^{1,12}$ Interfering with type 1 fimbriae-mediated mannose recognition events has thus been identified as a potential strategy for the development of an anti-adhesive therapy and be expected not to be inherently bactericidal or bacteriostatic, thus providing an additional alternative therapeutic strategy against targets including E. coli. ${ }^{13,14}$ However, the affinity of an individual FimH protein receptor for either mannose or highmannose glycans and even specifically designed synthetic monovalent mannoside-derived ligands is often disappointingly low and multivalent mannose-based alternatives have additionally been turned to in the search for potential anti-adhesives for E. coli. ${ }^{15}$ The underlying design principle resides in the fact that the affinities of lectins for their cognate carbohydrate ligand(s), when the latter are presented as multiple copies on biotic/abiotic surfaces, increases the affinities observed for the corresponding monovalent interactions.

A number of synthetic multivalent compounds have been shown to modulate carbohydratemediated binding events by successfully harnessing this "cluster effect". ${ }^{16-19}$ Nevertheless, even the best of the multivalent analogs thus-far reported for the inhibition of FimH-mediated adhesion of E. coli to eukaryotic cells ${ }^{20-24}$ have invariably been of the same potency range (when valency-corrected) or inferior to good small-molecule and cluster inhibitors. ${ }^{25}$ Nanodiamond particles (NDs) are emerging as particularly well-suited for biological applications due to their biocompatibility. ${ }^{26-30}$ It is indeed because of their high biocompatibility that diamond nanoparticles should also be explored for antibacterial applications. While nanodiamonds conjugates have shown their interest for the detection and 
removal of bacteria in solution, ${ }^{25}$ their potential for the efficient inhibition of FimH-mediated binding phenomena has however not been addressed yet. One of the advantages of nanodiamonds over other carbon-based materials such as fullerenes and carbon nanotubes is that they are completely inert, optical transparent, biocompatible and can furthermore be functionalized in many ways depending on their intended ultimate application. ${ }^{27,}$, 31-37 Although their in vivo toxicity depends on their particular surface characteristics, ${ }^{38} \mathrm{ND}$ particles do not induce significant cytotoxicity in a variety of cell types. ${ }^{38-41}$ Moreover, NDs may as a result of their intrinsic fluorescence properties prove very useful as biomarkers in living cells. ${ }^{42,} 43$ Despite their evident potential in biomedicine, studies reported on the biorecognition properties of functionalized NDs have nevertheless been relatively few. Aminophenylboronic acid-modified NDs have been shown to allow selective capture of glycoproteins from unfractionated protein mixtures. ${ }^{44}$ The large surface forces typical of NDs (mediated through electrostatic interactions) have been exploited for the pre-concentration of proteins. ${ }^{45}$ This latter example involves non-specific recognition properties of NDs and these have been also been harnessed for the detection of biomolecules such as cytochrome c, albumin, lyzosyme and DNA. ${ }^{46-48}$ We previously established for the first time that sugarfunctionalized diamond surfaces can adhere in a sugar-specific manner to lectins and can thereby provide an effective platform for interrogating carbohydrate-lectin binding events. ${ }^{49}$

In the present study, we present full details of our work on glycan-functionalized NDs (glycoNDs) as potent and specific anti-adhesives for E. coli adhesion to biotic surfaces and their interference with biofilm formation on abiotic surfaces. ${ }^{66}$ Glyco-NDs were constructed through the covalent conjugation of propargyl-terminated sugar components to azidefunctionalized NDs (Figure 2). Recently, mannose-derived biphenyl- and triazolefunctionalized FimH agonists have been reported to show large FimH-binding potencies compared to those reported for other monovalent ligands. ${ }^{50-53}$ In an approach, wherein aromatic azido analogs covalently incorporated on ND surfaces are "clicked" with alkynylfunctionalized mannosides through a Huisgen cycloaddition strategy, glyco-NDs composed of multiple mannose units each featuring the triazole-tethered aromatic motif reminiscent of previously reported potent monovalent FimH ligands were formed. ${ }^{50-52}$ The effectiveness of the newly fabricated mannose-derived glyco-NDs to inhibit bacterial adhesion to various eukaryotic cells was established by measuring their ability to block the adhesion of a genetically engineered $E$. coli $\mathrm{K}-12$ derivative strain constitutively expressing type 1 fimbriae to various eukaryotic cells (Figures 1A,B). It will be demonstrated, that the newly fabricated 
glyco-NDs functionalized with mannose units (ND-mannose) effectively inhibit type 1 fimbriae-mediated yeast-agglutination and human bladder-cell adherence in a sugar-selective manner. The eukaryotic cell-adherence inhibitory efficiency of ND-mannose revealed to be far superior to those reported for other glycan-modified particles and nanostructures directed against E. coli. In addition, we report, that these ND-Mannose display an E. coli biofilm inhibitory activity (Figure 1C), a property not previously reported for multivalent glyconanoparticles (glyco-NPs), and rarely for other sugar analogs specifically targeting FimH. ${ }^{50 \text {, }}$ 54

\section{EXPERIMENTAL}

Preparation of mannose-clicked NDs and other ND particles:

\section{Formation of azide-terminated ND (ND- $\left.N_{3}\right)$ particles}

4-Azidobenzoic acid (0.20 mmol, purchased from TCI Europe, Belgium), N,N'dicyclohexylcarbodiimide (DCC, $0.22 \mathrm{mmol}$ ) and 4-dimethylaminopyridine (DMAP, 0.066 mmol) were dissolved in $5 \mathrm{~mL}$ anhydrous acetonitrile. A suspension of ND-OH particles (International Technology Centre, Raleigh, NC, USA) in anhydrous acetonitrile (10 mg in 5 $\mathrm{mL}$ ) was added to the solution and stirred at room temperature for $24 \mathrm{~h}$ under nitrogen. The azido-terminated ND particles were isolated by centrifugation at $10.000 \mathrm{rpm}$, purified through four consecutive wash/centrifugation cycles at $10.000 \mathrm{rpm}$ with acetonitrile and ethanol, and finally oven dried at $50{ }^{\circ} \mathrm{C}$ for $24 \mathrm{~h}$.

\section{Formation of glycan-terminated ND (glyco-NDs) particles}

The azide-terminated $\left(\mathrm{ND}-\mathrm{N}_{3}\right)$ particles $(10 \mathrm{mg})$ were dispersed in water $(10 \mathrm{~mL})$ and sonicated for $30 \mathrm{~min}$. The "click" reaction was performed by addition of 1-alkynyl carbohydrates $(2 \mathrm{mM})$, copper(II) sulphate pentahydrate $\left(\mathrm{CuSO}_{4} .5 \mathrm{H}_{2} \mathrm{O} ; 200 \mu \mathrm{M}\right)$ and Lascorbic acid $(300 \mu \mathrm{M})$ to the ND-N 3 particles and subsequent stirring for $24 \mathrm{~h}$ at room temperature. The resulting nanoparticles were isolated by centrifugation at $10.000 \mathrm{rpm}$. In order to remove residual copper from the azide-alkyne Huisgen cycloaddition reaction, the first cleaning step consists of three additional washing/centrifugation cycles with EDTA solution (1 $\mathrm{mM}$ in water). Then, the second cleaning step consists of three consecutive washing/centrifugation cycles at $10000 \mathrm{rpm}$ with water and ethanol. In either case, the particles were finally oven dried at $50{ }^{\circ} \mathrm{C}$ for $24 \mathrm{~h}$.

\section{Determination of the carbohydrate quantity:}




\section{Direct method}

A calibration curve for carbohydrate concentrations in solution was established. For this, a phenolic aqueous solution $(5 \mathrm{wt} \%, 60 \mu \mathrm{L})$ and concentrated $\mathrm{H}_{2} \mathrm{SO}_{4}(900 \mu \mathrm{L})$ was added to an aqueous carbohydrate solution $(60 \mu \mathrm{L})$, stirred for $10 \mathrm{~min}$ and then an absorption spectrum of the mixture was recorded (Perkin Elmer Lambda 950 dual beam) against a blank sample (without carbohydrate). The absorbance of the solution was measured at two wavelengths: $\lambda_{1}=495$ and $\lambda_{2}=570 \mathrm{~nm}$ and the absorbance difference $\left(\mathrm{A}_{495}-\mathrm{A}_{570}\right)$ plotted against the concentration of the corresponding carbohydrate. The quantity of surface-linked carbohydrate on a glyco-ND was determined with $60 \mu \mathrm{L}$ of the corresponding ND particles solution in water $\left(0.8 \mathrm{mg} \mathrm{mL}{ }^{-1}\right)$, which was treated with phenol $/ \mathrm{H}_{2} \mathrm{SO}_{4}$ following the same protocol described above. Propargyl alcohol-terminated ND particles were treated in the same manner and used as a blank sample.

\section{Indirect method}

The sugar-functionalized ND particles were weighed out accurately $(0.25 \mathrm{mg}$ of NDs per $\mathrm{mL}$ ) and treated with an aqueous $\mathrm{LiOH}$ solution $(1 \mathrm{M})$ at room temperature for $24 \mathrm{~h}$ to hydrolyze the ester bond between the NDs and the molecular assembly including the carbohydrate function. After filtration, $60 \mu \mathrm{L}$ of the filtrate was treated with phenol/ $\mathrm{H}_{2} \mathrm{SO}_{4}$ following the same protocol as described above.

\section{Instrumentation}

Fourier transformed infrared spectroscopy: Fourier transform infrared (FT-IR) spectra were recorded using a Perkin-Elmer Spectrum One FT-IR spectrometer with a resolution of $4 \mathrm{~cm}^{-1}$. Dried ND powder $(1 \mathrm{mg})$ was mixed with $\mathrm{KBr}$ powder $(100 \mathrm{mg})$ in an agate mortar. The mixture was pressed into a pellet under 10 tons load for 2-4 min and the spectrum was recorded immediately. Sixteen accumulative scans were collected. The signal from a pure $\mathrm{KBr}$ pellet was subtracted as a background.

X-ray photoelectron spectroscopy: X-ray photoelectron spectroscopy (XPS) measurements were performed with an ESCALAB 220 XL spectrometer from Vacuum Generators featuring a monochromatic Al Ka X-ray source $(1486.6 \mathrm{eV})$ and a spherical energy analyzer operated in the $\mathrm{CAE}$ (constant analyzer energy) mode $(\mathrm{CAE}=100 \mathrm{eV}$ for survey spectra and $\mathrm{CAE}=40$ $\mathrm{eV}$ for high-resolution spectra), using the electromagnetic lens mode. No flood gun source was needed due to the conducting character of the substrates. The angle between the incident $\mathrm{X}$-rays and the analyzer is $58^{\circ}$. The detection angle of the photoelectrons is $30^{\circ}$. 
Particle size measurements: ND suspensions $\left(20 \mu \mathrm{g} \cdot \mathrm{mL}^{-1}\right)$ in water were sonicated. The particle size of the ND suspensions was measured at $25^{\circ} \mathrm{C}$ using a Zetasizer Nano ZS (Malvern Instruments S.A., Worcestershire, U.K.) in $173^{\circ}$ scattering geometry and the zeta potential was measured using the electrophoretic mode.

\section{Biological assays of mannose-terminated ND particles:}

\section{Bacterial cell strains}

GFP-labeled E. coli constituvely expressing the type 1 fimbriae fim operon under the control

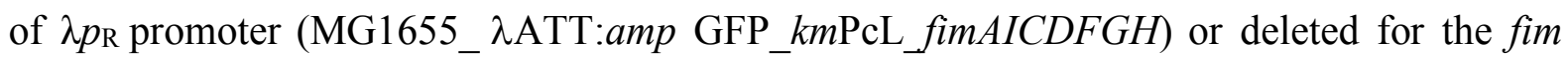

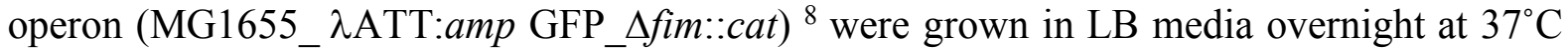
at 200 r.p.m. and diluted 1:100 to M63B1 minimal media supplemented with $0.4 \%$ glucose (M63B1-Gluc) for another $24 \mathrm{~h}$ in static conditions at $37{ }^{\circ} \mathrm{C}$. T24 human cell line derived from bladder cell (ATCC HTB-4) were grown in McCoy's 5A + Glutamax (Invitrogen) supplemented with $10 \%$ fetal bovine serum (FBS) and maintained at $37{ }^{\circ} \mathrm{C}$ and $5 \% \mathrm{CO}_{2}$. Cells were routinely split twice a week at a 1:5 ratio.

\section{Yeast agglutination assay}

E. coli MG1655_גATT:amp GFP_kmPcL_fimAICDFGH or deletion mutant

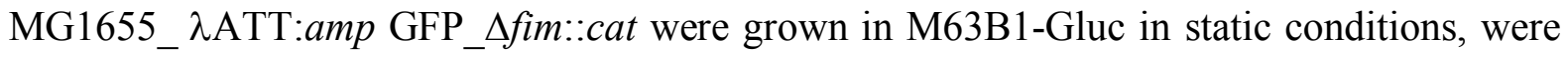
washed with 1 volume of PBS twice and diluted to optical density at $600 \mathrm{~nm}\left(\mathrm{OD}_{600}\right)$ of 0.8 . $5 \mu \mathrm{l}$ of each compound was added at the indicated concentration to $5 \mu \mathrm{L}$ of bacteria and incubated for $5 \mathrm{~min}$ at room temperature on a microscope slide. $10 \mu \mathrm{L}$ of $S$. cerevisiae washed twice in PBS and diluted to $\mathrm{OD}_{600} 1$ were mixed with the bacteria. Agglutination was observed under an optical microscope. The titre was considered as the lowest compound concentration that inhibits agglutination.

\section{Inhibition of bacterial binding to T24 bladder cells}

$10^{4} \mathrm{~T} 24$ bladder cells were seeded per well into a 96-well culture plates and incubated for 24 $\mathrm{h}$ in the same conditions. Cell monolayer was washed three times with PBS before adding bacteria. Static bacterial cultures grown in M63B1-Gluc were washed three times with PBS and re-suspended in McCoy's 5A medium + Glutamax (Invitrogen) and vigorously vortex in order to disperse bacterial clumps. $100 \mu \mathrm{L}$ of bacterial suspension were then added to the cell 
culture, centrifuged at 100 r.p.m. for $5 \mathrm{~min}$ and incubated at $37^{\circ} \mathrm{C}$ in $5 \% \mathrm{CO}_{2}$. After $40 \mathrm{~min}$ of incubation, cells were washed twice with PBS in order to eliminate non adherent bacteria. Attached bacteria were released with Triton X100 0.1\% in PBS and transferred to a Nunclon 96 flat bottom black plates and gfp fluorescence was measured in Infinite 200 (Tecan) plate reader. In order to establish the multiplicity of infection for each experiment, a bacterial suspension of $1.0 \mathrm{OD}_{600}$ was serially diluted and used to test binding. The bacterial $\mathrm{OD}_{600}$ used in the inhibition experiment corresponds to the amount of bacteria that allows $50 \%$ of total binding to T24 cells. This determined bacterial $\mathrm{OD}_{600}$ was used with the indicated NDs or $\alpha \mathrm{mmp}$ as control at different concentrations and incubated for $15 \mathrm{~min}$ at room temperature before the binding assay. In all cases the non fimbriated isogenic strain MG1655_ $\lambda$ ATT:amp GFP__fim::cat was used as control. Experiments were performed in triplicates at least 4 times and $\mathrm{IC}_{50}$ were obtained. Statistical analysis was performed using GraphPad Prism software.

\section{Toxicity assay}

T24 bladder cells were incubated with serially diluted indicated NDs for $24 \mathrm{~h}$. Cell growth was determined by the MTT reduction assay (Tox-1, Sigma Inc.). Experiments were performed in triplicate at least three times. Activity in the absence of drug was considered as $100 \%$. No significant difference was observed in the cell growth after $24 \mathrm{~h}$ with up to 1000 $\mu \mathrm{g} . \mathrm{mL}^{-1}$ of either galactose-clicked- or mannose-clicked NDs.

\section{Biofilm formation inhibition in microtiter plates}

The inhibition of biofilm formation was assayed by determining the ability of the cells to adhere to the wells of 96-well non-tissue culture-treated polyvinyl chloride (PVC) microtitre dishes ${ }^{55}$. Overnight cultures were adjusted to $\mathrm{OD}_{600} 0.1$ in M63B1Glu medium. Compounds were serially diluted in M63B1Glu medium. Equal volume of bacteria and each compounds dilution were mixed, and the $100 \mu \mathrm{L}$ mix was added to a 96-well PVC plate and incubated at $37^{\circ} \mathrm{C}$ for $24 \mathrm{~h}$ in a humid chamber. For biofilm detection, wells were rinsed, and $125 \mu \mathrm{L}$ of a $1 \%$ solution of crystal violet was added. The plates were incubated at room temperature for $15 \mathrm{~min}$ and rinsed, crystal violet was solubilized by addition of $150 \mu \mathrm{L}$ of ethanol/acetone (80:20), and the $\mathrm{OD}_{595}$ was determined. The results are averages of three replicate wells in three independent experiments. 


\section{RESULTS AND DISCUSSION}

\section{Construction of glycan-functionalized nanodiamonds}

We have previously shown that sugar-grafted diamond interfaces can be conveniently obtained in two steps by first fabricating alkynyl-terminated diamond through the reaction of its surface hydroxyl groups with 5-oxo-5-(prop-2-ynyloxy)pentanoic acid and then clicking them with azido-derivatized sugar partners using a copper(I) catalyzed Huisgen 1,3-dipolar cycloaddition protocol. Surfaces well-adapted for sensing specific carbohydrate interactions with lectin partnerss such as Lens Culinaris and PNA were obtained via this strategy. ${ }^{49}$ Motivated by these results, a related coupling strategy was devised in the present work using commercially available detonated hydroxyl-terminated ND particles (ND-OH). The diameter of the particles was $d=79 \pm 13 \mathrm{~nm}$ and showed a zeta potential of $\zeta=35.3 \pm 1.6 \mathrm{mV}$. We took advantage of the surface hydroxyl groups present on commercial NDs, and coupled them to 4-azidobenzoic acid in the presence of $N, N^{\prime}$-dicyclohexylcarbodiimide and a catalytic amount of 4-dimethylaminopyridine (Figure 2). ${ }^{32}$ We hypothesized that the surface-linked 4azidobenzoic ester group thus introduced, would serve both as the required "click" azido partner and as an integral aglycon segment of the FimH ligand in the knowledge that related mannose-derived biphenyl- and triazole-functionalized FimH agonists have been reported to be potent small molecule inhibitors of FimH-mediated E. coli adhesion events. ${ }^{50,51,56}$ The fabricated azide-functionalized ND particles $\left(\mathrm{ND}-\mathrm{N}_{3}\right)$ reacted smoothly with propargylated partners such as propargyl mannoside, propargyl galactoside or propargyl alcohol in the presence of $\mathrm{CuSO}_{4} / \mathrm{L}$-ascorbic acid as catalyst giving the corresponding mannose-clicked (ND-Mannose), galactose-clicked (ND-Galactose) and propargyl alcohol-clicked NDs (NDNo sugar) respectively (Figure 2).

The success of the surface-functionalization steps was followed by FT-IR spectroscopy (Figure 3A). The spectrum of the as-received ND-OH (Figure 3A-a, ND-OH) shows a broad peak at $3400 \mathrm{~cm}^{-1}$ assigned to the vibration of surface hydroxyl groups or/and adsorbed water molecules, and an additional sharper one at $1633 \mathrm{~cm}^{-1}$ due to the bending mode $\delta_{(\mathrm{OH})}$ of surface hydroxyl groups on the NDs. The C-H stretching vibration modes of $\mathrm{sp}^{3} / \mathrm{sp}^{2}$ bonding are detected at $2850-2970 \mathrm{~cm}^{-1}$ and are partially masked by the large band at $3400 \mathrm{~cm}^{-1}$. In addition, the band at $1107 \mathrm{~cm}^{-1}$ is indicative of the presence of $\mathrm{C}-\mathrm{O}-\mathrm{C}$ - functions of cyclic ethers. After reaction of ND-OH particles with 4-azidobenzoic acid in the presence of DCC and DMAP, new vibration peaks at 2123, 1717, 1610, 1375, and $1283 \mathrm{~cm}^{-1}$ appeared in the FT-IR spectrum (Figure 3A-b, ND-N $)$. The band at $2123 \mathrm{~cm}^{-1}$ is characteristic of $v_{\mathrm{as}}(\mathrm{N} 3)$ 
stretching. In addition, the band at $1717 \mathrm{~cm}^{-1}$, typical of $\mathrm{C}=\mathrm{O}$ stretching, confirms the formation of ester functions. "Clicking" of the propargyl-mannoside to ND-N 3 results in the generation of surface triazole groups that are identifiable from their characteristic FT-IR resonances (Figure 3A-c, ND-Mannose). The essentially quasi quantitative cycloaddition of propargyl-mannoside to azide groups is further evidenced by the complete disappearance of the $v_{\text {as(N3) }}$ stretching mode at $2123 \mathrm{~cm}^{1}$. The zeta potential fell to $\zeta=26.7 \pm 0.6 \mathrm{mV}$ upon mannoside grafting and the particle size increased to $\mathrm{d} \approx 155 \pm 4 \mathrm{~nm}$. Neither size nor zeta potential varied significantly in NDs featuring alternate "clicking" partners such as propargyl-galactoside or propargyl-alcohol. The galactose-clicked (Figure 3A-d, NDGalactose) and the propargyl alcohol-clicked NDs (Figure 3A-e, ND-No sugar) gave FT-IR data consistent with their structures. Previously, copper complexes have been demonstrated to be highly toxic for human cell lines ${ }^{10}$ and in order to ensure complete removal of residual copper after the azide-alkyne Huisgen cycloaddition reaction, a cleaning step was implemented which consisted of three additional washing/centrifugation cycles with EDTA solution in water. High resolution $\mathrm{Cu} 2 \mathrm{p}$ core level spectra of particles before (black) and after (grey) washing with EDTA were generated conveniently by photoelectron spectroscopy and confirmed the absence of copper after the washing procedure (Figure 3B).

The amounts of sugar clicked to a glyco-ND surface was quantified using two alternative assay formats, both of which are based on the phenol-sulfuric acid colorimetric method now well-established for analysis of carbohydrate on nanoparticles ${ }^{57,58}$. In one (termed indirect), sugars are first released from the glyco-NDs by treatment with lithium hydroxide and freed from solid debris before the sugar concentration of the supernatant was calculated from the measured absorption difference between $\lambda=570 \mathrm{~nm}$ (baseline) and $\lambda=495 \mathrm{~nm}$ with reference to a calibration curve (Figure 3C). In the alternative format (direct method) the glyco-NDs are subjected to the colorimetric assay without any prior pre-treatment (data not shown). The

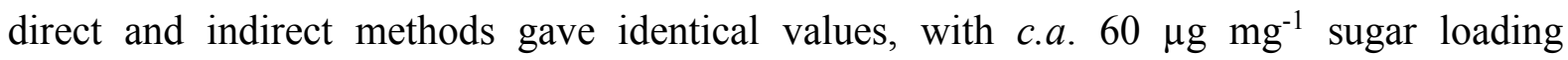
measured.

\section{Inhibition of type 1 fimbriae-mediated adhesion to eukaryotic surfaces with mannose- modified nanodiamonds}

We used two complementary assay formats to evaluate the potency and selectivity of the new glyco-NDs to interfere with type 1 fimbriae-mediated adhesion. The first reports on their ability to inhibit bacterial agglutination of yeast cells and the second on their efficacy to 
interfere with bacterial binding to eukaryotic bladder cells. Adhesion of E. coli to both yeast and human eukaryotic cells is dependent on the interaction of their surface presented FimH adhesins with mannosylated residues found on glycans at the surfaces of these eukaryotic cells. An E. coli K-12 strain, MG1655kmPcLfim, genetically modified to constitutively express the fim operon, encoding type 1 fimbriae surface appendages, was chosen for both assays (see Experimental). ${ }^{8}$

In the yeast agglutination assay, the inhibition titer was considered as the minimum concentration of each compound able to inhibit agglutination. The ND-No sugar and NDGalactose controls both showed, as expected, very little inhibitory effect at concentrations superior to $1000 \mu \mathrm{g} . \mathrm{mL}^{-1}$ (Table 1A and Figure S1). In contrast, ND-Mannose displayed high inhibitory potentials with valency-corrected titers of $6.8 \mu \mathrm{M}$ (Table 1A and Figure S1). The potency relative to that of methyl- $\alpha$-D-mannopyranoside (relative inhibition potency, RIP) of the mannose-functionalized NDs was as high as 1003.

The assessment of cytotoxicity is an important aspect during the development of novel nanomaterials. ${ }^{26,28-30,38,40}$ Incubation of the functionalized NDs for $24 \mathrm{~h}$ with T24 bladder cells established that NDs were non-toxic to these cells up to ND concentrations of 500 $\mu \mathrm{g} \cdot \mathrm{mL}^{-1}$ (Figure 4).

The potency of ND-Mannose to interfere with type 1 mediated adhesion events to human bladder cells was determined using a fluorescence assay. Evaluation of the inhibition of bacterial adhesion showed that ND-Mannose exhibit low, valence-corrected $\mathrm{IC}_{50 \mathrm{~s}}$ of $2.7 \mu \mathrm{M}$ (Table 1B). This corresponds to a RIP value of 9259 (Figure 5 and Table 1B). Neither the ND-No sugar or the ND-Galactose controls displayed any capacity to inhibit E. coli adhesion to human bladder cells (Table 1B and Figure 5). A handful of sugar- or protein-functionalized NPs have been previously assayed against E. coli, including several based on carbon platforms, but these have primarily been limited to the labeling or capture of the bacteria. ${ }^{58-61}$ Thus the newly fabricated mannose-modified NDs are seen to show a very marked inhibitory activity of bacterial binding to either human or yeast cells and significantly better than those measured for other mannose-functionalized multivalent NPs such as those based on either gold (RIP of c.a. 20) ${ }^{20}$ or fullerenes (RIP of c.a. 3). ${ }^{58}$ While the reason for this increase is still under investigation, it can be most likely put down to their more efficient harnessing of a multivalency effect. These striking differences are most probably driven in part by the intrinsic physicochemical properties of the ND core and its dimensions as well as to the fact that mannoside moieties are linked to this core via an aromatic triazole tether motif expected 
to be a much better ligand for FimH than mannose alone or mannopyranosyl ligands grafted through alternate chemical linkers (such as those previously reported for multivalent glycoNPs directed against $E$. coli).

Furthermore, assuming that variations between assay methods between authors are insignificant, ND-Mannose is seen always to perform much better than alternate multivalent platforms such as mannose-terminated clusters and glyco-dendrimeric structures reported previously. ${ }^{15}$ Nevertheless, the non-equilibrium nature of the binding processes likely driving the strikingly high avidities observed for the fabricated ND-Mannose which include NPaggregation, lectin-bridging, lectin-NP aggregation, etc., together with the heterogenous nature of the surface mannoside derivatization of these novel glyco-NDs, suggest that the molecular basis of the observed enhancement would be complex. ${ }^{14,18,24,62}$

\section{Mannose-modified nanodiamonds can also inhibit type 1 fimbriae-mediated biofilm formation}

In addition to their role in adhesion to cell surfaces, type 1 fimbriae are well-known to promote adhesion to abiotic surfaces and to enhance biofilm formation. The initial attachment and establishment of E. coli $\mathrm{K}-12$ biofilms to abiotic surfaces can be blocked by mannosides thus indicating an active role of FimH lectin in this process. ${ }^{5}$ We therefore evaluated the ability of ND-Mannose to inhibit biofilm formation on polyvinyl chloride (PVC) surfaces. While ND-No sugar particles have only very weak impact on type 1 fimbriated $E$. coli biofilm formation, ND-Mannose particles display a significant inhibition on biofilm growth on PVC interfaces (Figure 6A), being 100-fold higher than monovalent mannosides (at equivalent concentrations) used as control. The biofilm inhibition is concentration-dependent as well as time dependent. Since concentration of up to $180 \mu \mathrm{M}$ [carbohydrate] ND-Mannose had no or marginal effect on E. coli growth per se (Figure 6B) we conclude that NDMannose particles exert their biofilm-inhibition effect by reducing the interaction of FimH with PVC surfaces. However, ND-Mannose particles added after $24 \mathrm{~h}$ of bacterial growth were unable to disrupt already established biofilms (data not shown) demonstrating that these particles cannot counteract pre-established interactions between FimH and abiotic surfaces. This is perhaps due to the dense exopolymeric matrix characteristic of established biofilms that would be expected to hinder the accessibility of the glyco-NDs to the bacterial surface. 
In order to visualize how ND-Mannose interferes with type 1 fimbriae-mediated adhesion, transmission electron microscopy was performed on samples where bacteria had been treated with sugar-functionalized NDs (Figure 7). ND-Galactose did not show any binding to fimbriated cells (Figure 7a) whereas ND-Mannose particles were clearly aggregated around fimbriated bacteria (Figure 7c). Further, ND-Mannose particles also apparently display the capacity of bridging multiple $E$. coli cells due to their ability to form aggregates (Figure $7 \mathrm{~b}$ ). Furthermore no or scarcely any binding was observed for ND-Mannose on afimbriated cells (Figure 7d).

In addition to establishing that the adhesion of ND-Mannose to E. coli is FimH-specific, these observations suggest that the glyco-ND particles reduce E. coli biofilm formation by saturation of groups of FimH protein covering limited but significant patches of the cellsurface of individual E. coli and thereby interfer effectively with FimH-mediated binding to abiotic surfaces. These are the first multivalent glyco-NPs demonstrated to reduce E. coli biofilm formation through a FimH related mechanism, although recently multivalent glycodendrimeric structures were reported to disrupt Pseudomonas aeruginosa biofilms albeit through a non fimbriae lectin-mediated pathway. ${ }^{63,64}$

\section{CONCLUSIONS}

We have successfully decorated diamond nanoparticles with glycans using a mild and versatile "click" chemistry approach. The incorporation of aromatic azide functions on hydroxylated nanodiamond particles allows the linking of alkynyl-functionalized glycosides through a Huisgen cycloaddition, to give nanodiamonds tethered with multiple mannoside moieties each featuring an aromatic triazole motif characteristic of recently described potent FimH ligands. The mannose-modified nanoparticles prove to be non-toxic to T24 bladder cells up to concentrations of $500 \mu \mathrm{g} \cdot \mathrm{mL}^{-1}$. This high biocompatibility highlights one of the unique advantages of diamond nanoparticles over other nanoparticles explored for similar applications. It has important consequences for potential implant applications as nanodiamonds can be considered a relatively safe material. The particles were further investigated for antibacterial applications. We show that these mannose-modified nanodiamond particles behave as highly specific anti-adhesives for E. coli adhesion to biotic as well as abiotic surfaces. The potencies observed for the ND-Mannose with RIPs of as high as 1003 (yeast agglutination assay) and 9259 (bladder cell adhesion assay), contrast dramatically with those reported for alternate mannose-functionalized NPs, such as those 
derived from gold (RIP of c.a. 20) or fullerene (RIP of c.a. 3). ${ }^{20,58}$ While the reason for this increase is still under invesstigation, the low micromolar range of affinity of the NDMannose described here and the reported absence of in vivo toxicity of NDs is compatible with their future evaluation in a clinical setting. Moreover, pharmacokinetics studies performed on rats by Rojas et al. reported that properly size-filtered NDs are excreted by the urinary tract without significant accumulation in other organs. ${ }^{65}$

Furthermore, we show here that ND-Mannose is endowed with the ability to block type 1 fimbriae-mediated biofilm formation. This feature suggests that the ND-Mannose may also have potential in countering E. coli-biofilm related infections contracted from contaminated medical devices such as urinary catheters as well as having potential in disrupting Intracellular Bacterial Communities (IBCs). Formation of IBCs is one of the primary causes of antimicrobial tolerance as well as infection relapse after antibiotic treatment as they serve as a reservoir of bacteria that are later released into the bladder. Anti-adhesives targeting $E$. coli infections have long been sought after as a potential therapeutic strategy as effective antiadhesive drugs would be expected to have an advantage over either bactericidal or bacteriostatic therapies, in being less prone to encourage resistant strains. Taken together the findings presented here for the newly fabricated glyco-NDs support, for the first time, that properly designed multivalent glyco-NPs that possess useful inhibitory activities against $E$. coli can indeed be fabricated, and should be further developed and evaluated as potential antiadhesives for countering bacterial colonization and infection in vivo.

\section{ACKNOWLEDGEEMNTS}

A.B, R.B, A.S and S.S. gratefully acknowledge financial support from the Centre National de Recherche Scientifique (CNRS), the Université Lille 1 and the Nord Pas de Calais region. A.S. gratefully acknowledges financial support and a postdoctoral fellowship to O.B. from the IFCPAR (Project 3905-1). Support from the Region Picardie is acknowledged for a doctoral fellowship for J.-S.B. This work was supported by grants from the Institut Pasteur and from the French Government's Investissement d'Avenir program, Laboratoire d'Excellence "Integrative Biology of Emerging Infectious Diseases" (grant nºNR-10LABX-62-IBEID). We are especially grateful to Brigitte Arbeille and Claude Lebos (LBCME, Faculté de Médecine de Tours) for their help in performing electronic microscopy. 


\section{REFERENCES}

1. P. Klemm, L. Hjerrild, M. Gjermansen and M. A. Schembri, Mol Microbiol, 2004, 51, 283-296.

2. C. Beloin, A. Roux and J. M. Ghigo, Curr Top Microbiol Immunol, 2008, 322, 249289.

3. A. L. Cookson, W. A. Cooley and M. J. Woodward, Int J Med Microbiol, 2002, 292, 195-205.

4. P. E. Orndorff and C. A. Bloch, Microb Pathog, 1990, 9, 75-79.

5. L. A. Pratt and R. Kolter, Mol Microbiol, 1998, 30, 285-293.

6. I. Adlerberth, L. A. Hanson, C. Svanborg, A. M. Svennerholm, S. Nordgren and A. E. Wold, Microb Pathog, 1995, 18, 373-385.

7. C. S. Eden and H. A. Hansson, Infect Immun, 1978, 21, 229-237.

8. C. G. Korea, R. Badouraly, M. C. Prevost, J. M. Ghigo and C. Beloin, Environ Microbiol, 2010, 12, 1957-1977.

9. E. V. Sokurenko, M. A. Schembri, E. Trintchina, K. Kjaergaard, D. L. Hasty and P. Klemm, Mol Microbiol, 2001, 41, 675-686.

10. S. Tardito, I. Bassanetti, C. Bignardi, L. Elviri, M. Tegoni, C. Mucchino, O. Bussolati, R. Franchi-Gazzola and L. Marchio, J Am Chem Soc, 2011, 133, 62356242.

11. R. Virkola, FEMS microbiology letters, 1987, 40, 257-262.

12. X. R. Wu, T. T. Sun and J. J. Medina, Proc Natl Acad Sci U S A, 1996, 93, 96309635.

13. I. Ofek, D. L. Hasty and N. Sharon, FEMS Immunol Med Microbiol, 2003, 38, 181191.

14. N. Jayaraman, Chem Soc Rev, 2009, 38, 3463-3483.

15. M. Hartmann and T. K. Lindhorst, Eur J Org Chem, 2011, 3583-3609.

16. L. L. Kiessling, J. E. Gestwicki and L. E. Strong, Curr Opin Chem Biol, 2000, 4, 696703.

17. J. J. Lundquist and E. J. Toone, Chem Rev, 2002, 102, 555-578.

18. M. Mammen, S.-K. Choi and G. M. Whitesides, Angewandte Chemie International Edition, 1998, 37, 2754-2794.

19. Y. C. Lee and R. T. Lee, Accounts for Chemical Research, 1995, 28, 321-327.

20. C. C. Lin, Y. C. Yeh, C. Y. Yang, C. L. Chen, G. F. Chen, C. C. Chen and Y. C. Wu, $J$ Am Chem Soc, 2002, 124, 3508-3509.

21. N. Nagahori, R. T. Lee, S. Nishimura, D. Page, R. Roy and Y. C. Lee, Chembiochem, 2002, 3, 836-844.

22. A. Patel and T. K. Lindhorst, Carbohydr Res, 2006, 341, 1657-1668.

23. M. Touaibia, A. Wellens, T. C. Shiao, Q. Wang, S. Sirois, J. Bouckaert and R. Roy, ChemMedChem, 2007, 2, 1190-1201.

24. R. J. Pieters, Org Biomol Chem, 2009, 7, 2013-2025.

25. M. Hartmann, P. Betz, Y. Sun, S. N. Gorb, T. K. Lindhorst and A. Krueger, Chemistry, 2012, 18, 6485-6492.

26. E. K. Chow, X. Q. Zhang, M. Chen, R. Lam, E. Robinson, H. Huang, D. Schaffer, E. Osawa, A. Goga and D. Ho, Sci Transl Med, 2011, 3, 73ra21.

27. V. N. Mochalin, O. Shenderova, D. Ho and Y. Gogotsi, Nat Nanotechnol, 2012, 7, $11-23$.

28. X. Zhang, W. Hu, J. Li, L. Tao and Y. Wei, Toxicology Research, 2012, 1, 62. 
29. X. Zhang, J. Yin, C. Kang, J. Li, Y. Zhu, W. Li, Q. Huang and Z. Zhu, Toxicology Letters, 2010, 198, 237-243.

30. Y. Zhu, J. Li, W. Li, Y. Zhang, X. Yang, N. Chen, Y. Sun, Y. Zhao, C. Fan and Q. Huang, Theranostics, 2012, 2, 302-312.

31. A. Barras, J. Lyskawa, S. Szunerits, P. Woisel and R. Boukherroub, Langmuir, 2011, 27, 12451-12457.

32. A. Barras, S. Szunerits, L. Marcon, N. Monfilliette-Dupont and R. Boukherroub, Langmuir, 2010, 26, 13168-13172.

33. Y. R. Chang, H. Y. Lee, K. Chen, C. C. Chang, D. S. Tsai, C. C. Fu, T. S. Lim, Y. K. Tzeng, C. Y. Fang, C. C. Han, H. C. Chang and W. Fann, Nat Nanotechnol, 2008, 3, 284-288.

34. S. A. Dahoumane, M. N. Nguyen, A. Thorel, J. P. Boudou, M. M. Chehimi and C. Mangeney, Langmuir, 2009, 25, 9633-9638.

35. A. Krüger, Angew Chem Int Ed Engl, 2006, 45, 6426-6427.

36. A. Krüger, J. Stegk, Y. Liang, L. Lu and G. Jarre, Langmuir, 2008, 24, 4200-4204.

37. Y. Liang, M. Ozawa and A. Krueger, ACS Nano, 2009, 3, 2288-2296.

38. L. Marcon, F. Riquet, D. Vicogne, S. Szunerits, J.-F. Bodart and R. Boukherroub, Journal of Materials Chemistry, 2010, 20, 8064-8069.

39. K. K. Liu, C. L. Cheng, C. C. Chang and J. I. Chao, Nanotechnology, 2007, 18, 325102.

40. A. M. Schrand, H. Huang, C. Carlson, J. J. Schlager, E. Omacr Sawa, S. M. Hussain and L. Dai, J Phys Chem B, 2007, 111, 2-7.

41. S. J. Yu, M. W. Kang, H. C. Chang, K. M. Chen and Y. C. Yu, J Am Chem Soc, 2005, 127, 17604-17605.

42. O. Faklaris, D. Garrot, V. Joshi, F. Druon, J. P. Boudou, T. Sauvage, P. Georges, P. A. Curmi and F. Treussart, Small, 2008, 4, 2236-2239.

43. Y. Y. Hui, C. L. Cheng and H. C. Chang, J Phys D Appl Phys, 2010, 43, 374021.374021-374021.374011.

44. W. S. Yeap, Y. Y. Tan and K. P. Loh, Anal Chem, 2008, 80, 4659-4665.

45. L. C. Huang and H. C. Chang, Langmuir, 2004, 20, 5879-5884.

46. X. Q. Zhang, M. Chen, R. Lam, X. Xu, E. Osawa and D. Ho, ACS Nano, 2009, 3, 2609-2616.

47. X. L. Kong, L. C. L. Huang, C. M. Hsu, W. H. Chen, C. C. Han and H. C. Chang, Anal Chem, 2004, 77, 259-265.

48. T. T.-B. Nguyen, H.-C. Chang and V. W.-K. Wu, Diamond and Related Materials , 2007, 16, 872-876.

49. S. Szunerits, J. Niedziolka-Jonsson, R. Boukherroub, P. Woisel, J. S. Baumann and A. Siriwardena, Anal Chem, 2010, 82, 8203-8210.

50. C. K. Cusumano, J. S. Pinkner, Z. Han, S. E. Greene, B. A. Ford, J. R. Crowley, J. P. Henderson, J. W. Janetka and S. J. Hultgren, Sci Transl Med, 2011, 3, 109 ra1 15.

51. Z. Han, J. S. Pinkner, B. Ford, E. Chorell, J. M. Crowley, C. K. Cusumano, S. Campbell, J. P. Henderson, S. J. Hultgren and J. W. Janetka, J Med Chem, 2012, 55, 3945-3959.

52. Z. Han, J. S. Pinkner, B. Ford, R. Obermann, W. Nolan, S. A. Wildman, D. Hobbs, T. Ellenberger, C. K. Cusumano, S. J. Hultgren and J. W. Janetka, J Med Chem, 2010, 53, 4779-4792.

53. O. Schwardt, S. Rabbani, M. Hartmann, D. Abgottspon, M. Wittwer, S. Kleeb, A. Zalewski, M. Smiesko, B. Cutting and B. Ernst, Bioorg Med Chem, 2011, 19, 64546473. 
54. A. Wellens, C. Garofalo, H. Nguyen, N. Van Gerven, R. Slattegard, J. P. Hernalsteens, L. Wyns, S. Oscarson, H. De Greve, S. Hultgren and J. Bouckaert, PLoS One, 2008, 3, e2040.

55. A. Roux, C. Beloin and J. M. Ghigo, J Bacteriol, 2005, 187, 1001-1013.

56. S. K. Saha and C. F. Brewer, Carbohydr Res, 1994, 254, 157-167.

57. X. Wang, O. Ramstrom and M. Yan, Journal of Materials Chemistry, 2009, 19, 89448949.

58. M. Durka, K. Buffet, J. Iehl, M. Holler, J. F. Nierengarten, J. Taganna, J. Bouckaert and S. P. Vincent, Chem Commun (Camb), 2011, 47, 1321-1323.

59. S. Campuzano, J. Orozco, D. Kagan, M. Guix, W. Gao, S. Sattayasamitsathit, J. C. Claussen, A. Merkoci and J. Wang, Nano Lett, 2012, 12, 396-401.

60. L. Gu, T. Elkin, X. Jiang, H. Li, Y. Lin, L. Qu, T. R. Tzeng, R. Joseph and Y. P. Sun, Chem Commun (Camb), 2005, 874-876.

61. H. Wang, T. B. Huff, D. A. Zweifel, W. He, P. S. Low, A. Wei and J. X. Cheng, Proc Natl Acad Sci U S A, 2005, 102, 15752-15756.

62. E. Arranz-Plaza, A. S. Tracy, A. Siriwardena, J. M. Pierce and G. J. Boons, J Am Chem Soc, 2002, 124, 13035-13046.

63. E. M. Johansson, S. A. Crusz, E. Kolomiets, L. Buts, R. U. Kadam, M. Cacciarini, K. M. Bartels, S. P. Diggle, M. Camara, P. Williams, R. Loris, C. Nativi, F. Rosenau, K. E. Jaeger, T. Darbre and J. L. Reymond, Chem Biol, 2008, 15, 1249-1257.

64. R. U. Kadam, M. Bergmann, M. Hurley, D. Garg, M. Cacciarini, M. A. Swiderska, C. Nativi, M. Sattler, A. R. Smyth, P. Williams, M. Camara, A. Stocker, T. Darbre and J. L. Reymond, Angew Chem Int Ed Engl, 2011, 50, 10631-10635.

65. S. Rojas, J. D. Gispert, R. Martin, S. Abad, C. Menchon, D. Pareto, V. M. Victor, M. Alvaro, H. Garcia and J. R. Herance, ACS Nano, 2011, 5, 5552-5559.

66. A. H. Siriwardena, A. Barras, F.A. Martin, O. Bande, J.-S. Baumann, J.-M. Ghigo, C. Beloin, R. Boukherroub, S. Szunerits, Glycoconjugate J., 2011, 28, 197 
(A)

\begin{tabular}{lllll}
\hline Compound & Valency & IT $\left(\mu \mathrm{g} \cdot \mathrm{mL}^{-1}\right)^{\mathrm{a}}$ & $\mathrm{RIT}(\mu \mathrm{M})^{\mathrm{a}}$ & $\mathrm{RIP}^{\mathrm{a}}$ \\
\hline $\begin{array}{l}\text { methyl- } \boldsymbol{\alpha}-\mathrm{D}- \\
\text { mannopyranoside } \\
\text { (positive control) }\end{array}$ & 1 & - & 7000 & 1 \\
& & & & \\
ND-No sugar & control & $>1000$ & $\mathrm{~b}$ & $\mathrm{~b}$ \\
ND-Galactose & 3.2 & 624 & 200 & 35 \\
ND-Mannose & 3.6 & 19.4 & 6.98 & 1003 \\
\hline
\end{tabular}

${ }^{\text {a }} \mathrm{IT}=$ inhibition titre, RIT $=$ relative inhibition titre $=\mathrm{IT} \times 0.32 \mu \mathrm{mol} / \mathrm{mg}$ for galactose or IT $\mathrm{x}$ $0.36 \mu \mathrm{mol} / \mathrm{mg}$ for mannose, RIP= relative inhibition potency = RIT of methyl- $\alpha-\mathrm{D}-$ mannopyranoside/RIT of ND-Galactose or of ND-Mannose. All relative inhibition parameters are expressed as micromolar concentration of carbohydrate.

${ }^{\mathrm{b}}$ Values cannot be estimated

(B)

\begin{tabular}{llll}
\hline Compound & $\begin{array}{l}\mathrm{IC}_{50} \\
\left(\mu \mathrm{g} \cdot \mathrm{mL}^{-1}\right)\end{array}$ & $\mathrm{RIC}_{50}(\mu \mathrm{M})^{\mathrm{a}}$ & $\mathrm{RIP}^{\mathrm{a}}$ \\
\hline $\begin{array}{c}\text { methyl- } \boldsymbol{\alpha}-\mathrm{D}- \\
\text { mannopyranoside }\end{array}$ & - & $25000.7 \pm 1.3$ & 1
\end{tabular}

(positive control)

$\begin{array}{llll}\text { ND-No sugar } & >500 & \mathrm{~b} & \mathrm{~b} \\ \text { ND-Galactose } & >500 & \mathrm{~b} & \mathrm{~b} \\ \text { ND-Mannose } & 7.6 \pm 0.7 & 2.7 \pm 0.5 & 9259\end{array}$

${ }^{\text {a }} \mathrm{RIC}_{50}=$ relative $\mathrm{IC}_{50}=\mathrm{IC}_{50} \times 0.36 \mu \mathrm{mol} / \mathrm{mg}$ for mannose, $\mathrm{RIP}=$ relative inhibition potency $=\mathrm{RIC}_{50}$ of methyl- $\alpha$-D-mannopyranoside/RIC $\mathrm{R}_{50}$ of ND-Mannose

${ }^{\mathrm{b}}$ Sigmoidal fit cannot be adjusted to data, values are not calculated

Table 1. Inhibition of A) bacterial yeast agglutination (YA) and B) bacterial cell adhesion by NDs. YA titre was determined as the minimal concentration of compound that was able to inhibit agglutination. In the cell adhesion assay, bacteria were added to cells and incubated during $60 \mathrm{~min}$ at $37^{\circ} \mathrm{C}$. Later, unbound bacteria were washed away and the quantity of remaining attached bacteria was determined by fluorescence in a black 96-well plate (Nunc) with an Infinity 200 Pro plate reader (Tekan Inc). The levels of fluorescence were normalized between $100 \%$ (no compound) and $0 \%$ (non-fimbriated E. coli $\Delta$ fim binding) and sigmoidal curves were adjusted Using GraphPad Prism 5.0 (GraphPad Sofware, San Diego, CA, USA). Both types of experiments were performed at least in triplicate in three independent experiments. Data are means $\mathrm{IC}_{50} \pm$ S.E.M, $\mathrm{n}=4$. (Valencies for ND-Galactose and ND- 
Mannose were calculated as follows: for ND-Galactose, we obtained $58 \mu \mathrm{g}$ of sugar per mg of ND corresponding to $0.32 \mu \mathrm{mol}$ of sugar par $\mathrm{mg}$ of ND, ie valency of 3.2 galactose per ND primary particles (primary average particle size $=4 \mathrm{~nm}$ ) ; for ND-Mannose, we obtained $65 \mu \mathrm{g}$ of sugar per mg of ND corresponding to $0.36 \mu \mathrm{mol}$ of sugar par mg of ND, ie valency of 3.6 mannose per ND primary particles (primary average particle size $=4 \mathrm{~nm}$ )). 

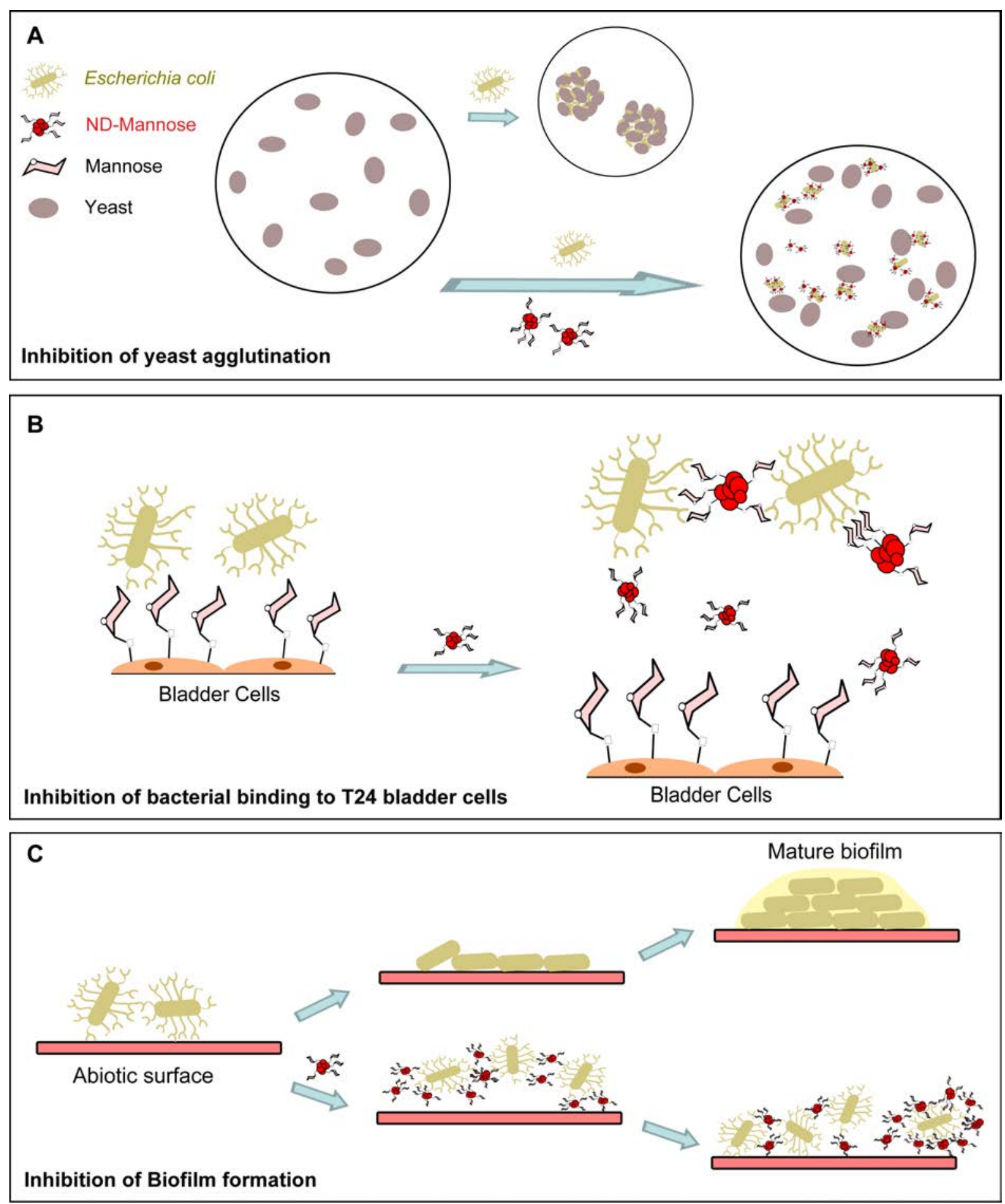

Figure 1. Schematic representation of ND-Mannose ability to counteract FimH-mediated adhesion. Capacity of ND-Mannose to interfer with type 1 fimbriae-mediated adhesion to eukaryotic cells was demonstrated using yeast agglutination inhibition assay (A) as well as inhibition of $E$. coli adhesion to bladder epithelial cells (B). In addition, ND-Mannose were demonstrated to be inhibitors of E. coli biofilm formation (C). 
Step 1

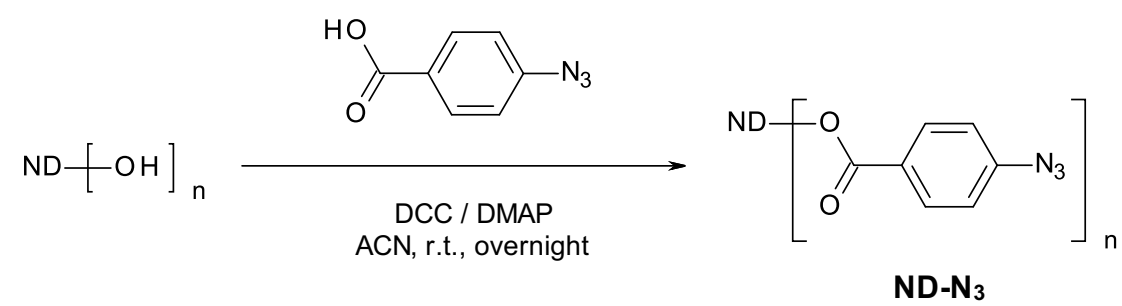

Step 2
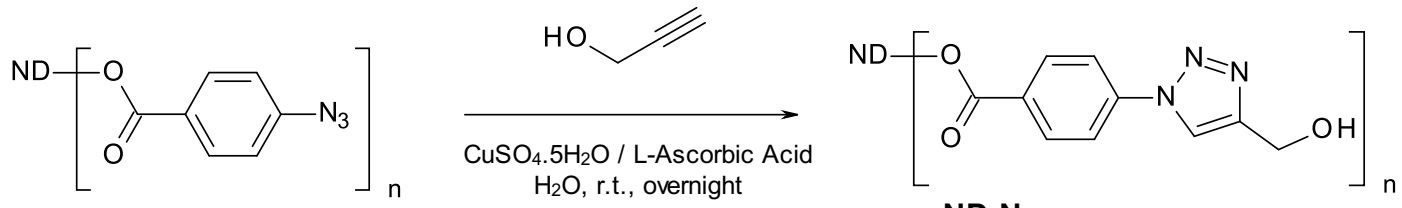

ND-No sugar<smiles>Nc1ccc(C(=O)O[Na])cc1</smiles>
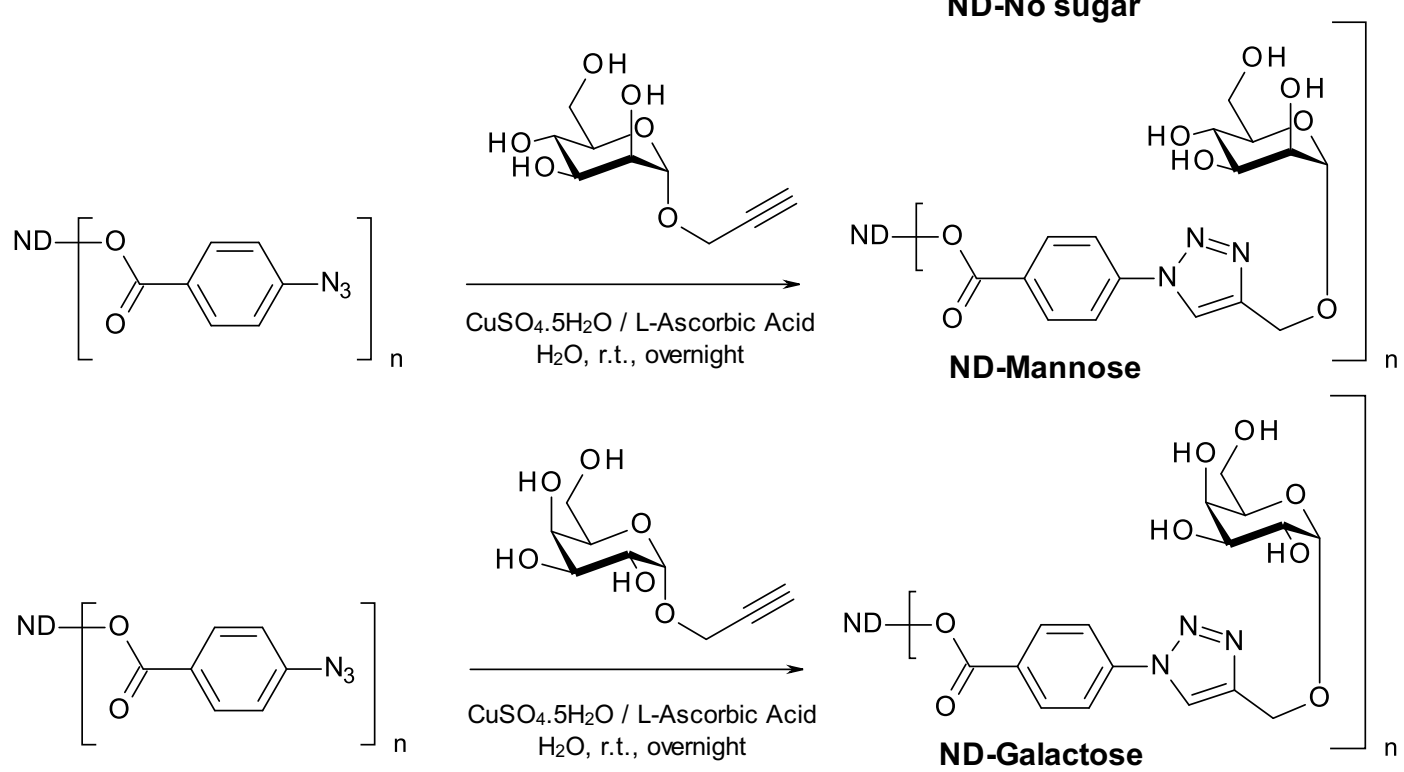

Figure 2. Schematic illustration of the chemical functionalization of ND particles via an azide-alkyne Huisgen cycloaddition reaction. 
A

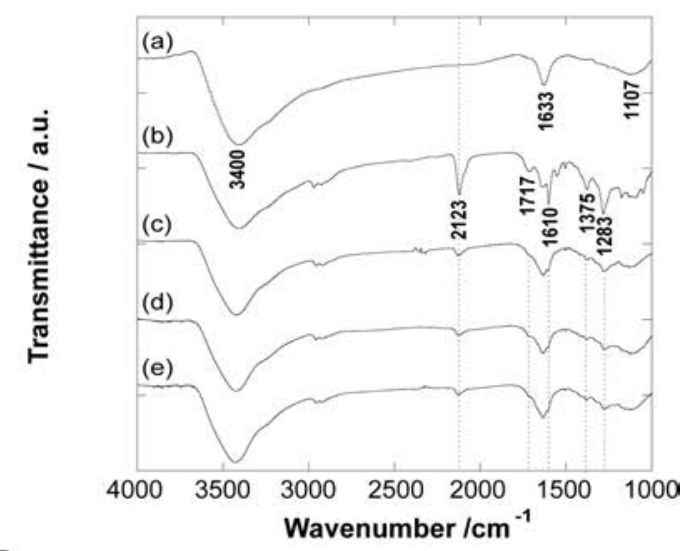

B
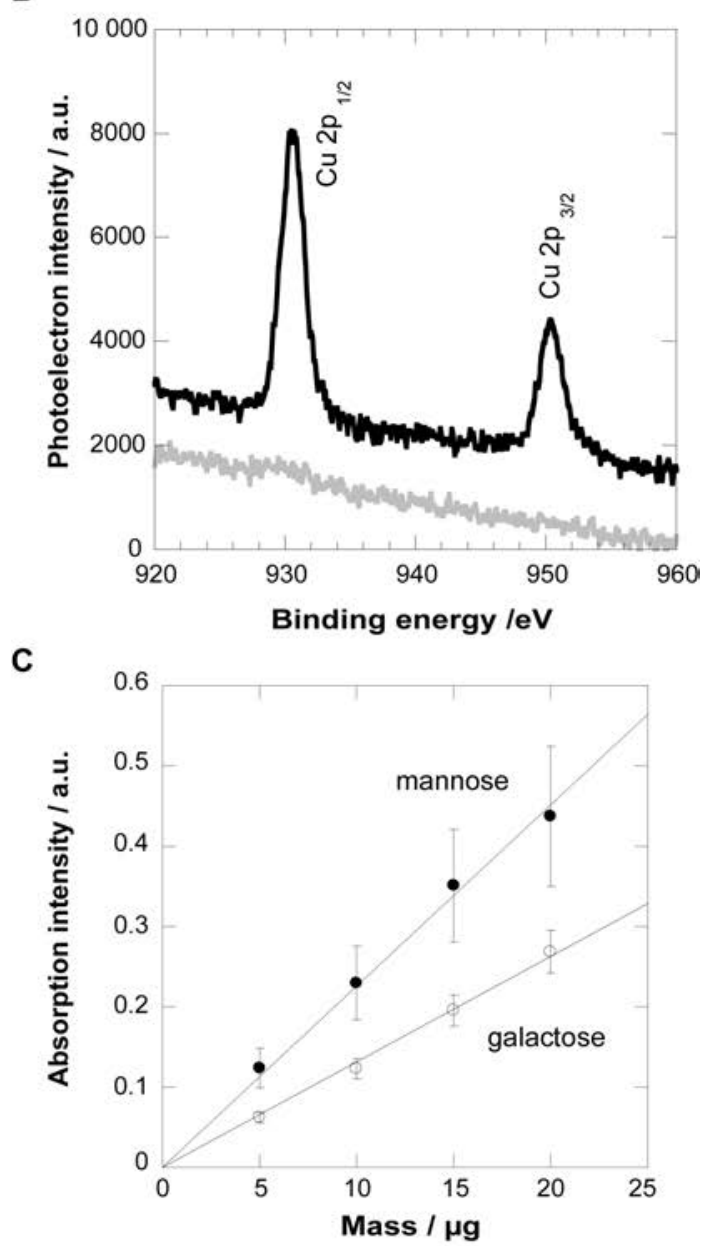

Figure 3. Characterization of glycan-functionalized nanodiamonds. A) Transmission FT-IR spectra of ND particles before and after functionalization of commercially available detonated NDs: (a) As-received ND-OH, (b) ND-N3, (c) ND-Mannose, (d) ND-Galactose and (e) ND-No sugar; B) High resolution Cu2p core level spectra of particles before (black) and after (grey) washing with EDTA; C) Calibration curves for mannose and galactose determined by a calorimetric method using phenol/sulfuric acid. 


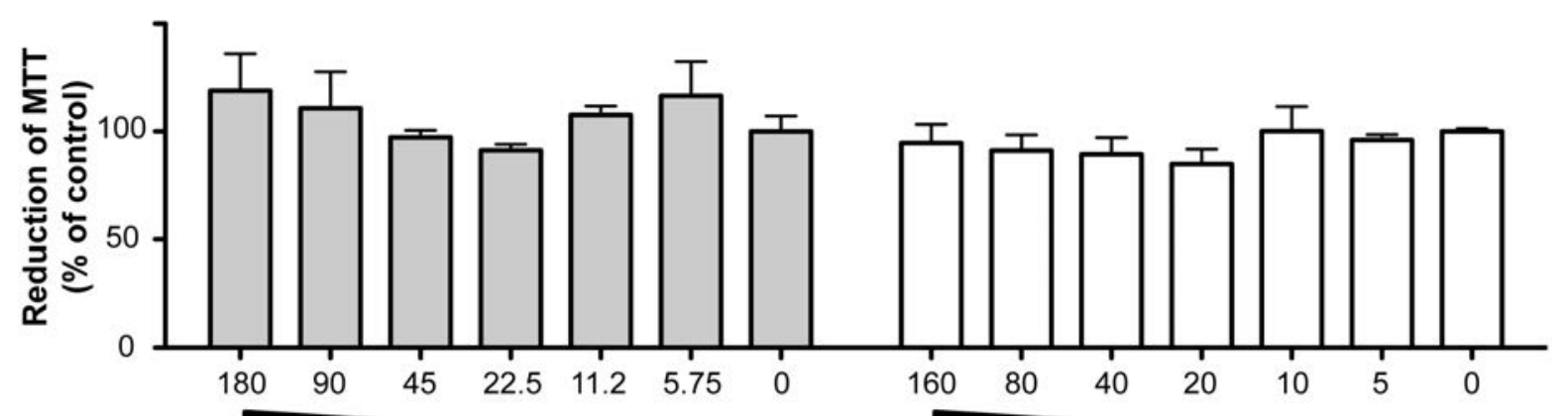

[ND-Mannose], $\mu \mathrm{M}$

[ND-Galactose], $\mu \mathrm{M}$

Figure 4. Toxicity of NDs on T24 bladder cells. T24 bladder cells were incubated during 24 $h$ in the presence of ND-Mannose or ND-Galactose. Neither the presence of ND-Mannose or ND-Galactose effect cell proliferation measured as the reduction of MTT. 


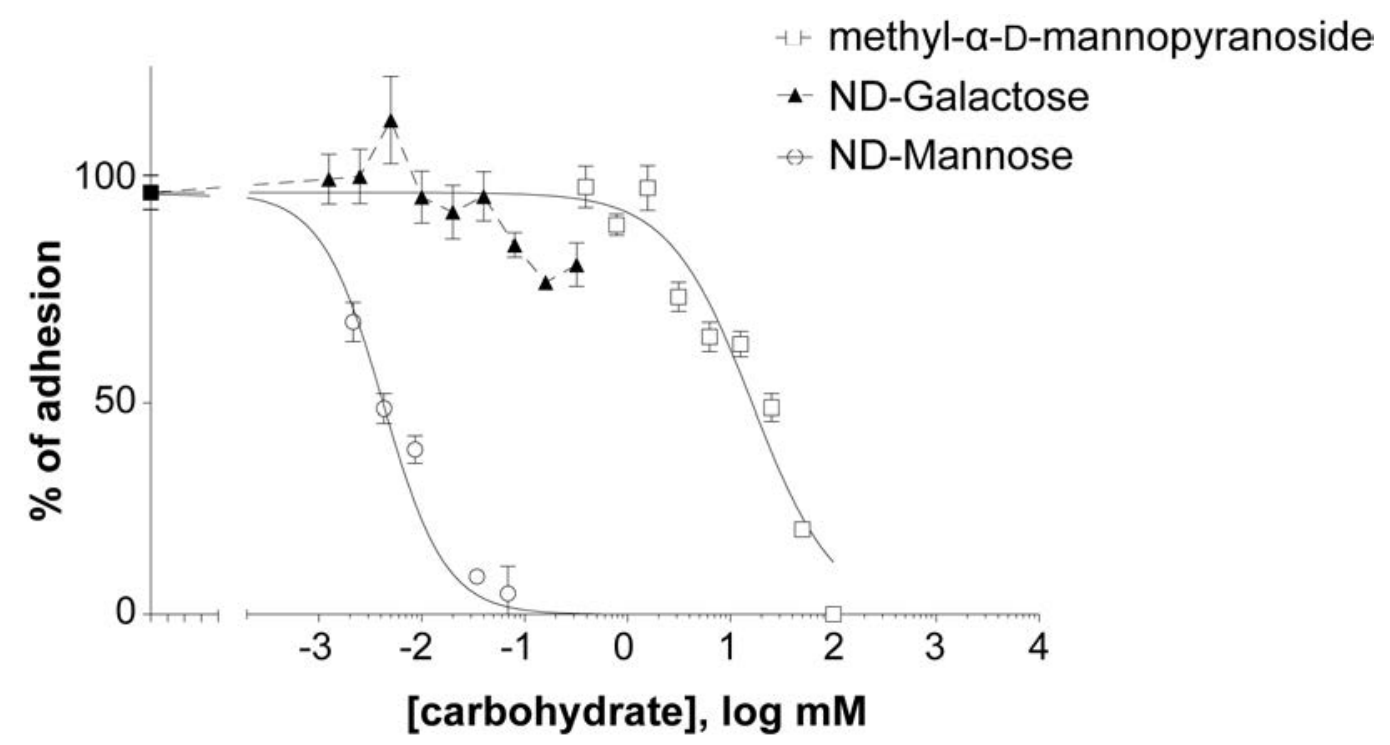

Figure 5. Mannose-clicked NDs inhibit binding of type 1 fimbriated cells to T24 epithelial bladder cells. Bacteria were incubated with varying concentrations of each compound to be tested and added to a confluent T24 cells monolayer on 96 well plates. After washing, the attached bacteria were measured by fluorescence in an Infinity 200 (Tecan) plate reader and expressed as relative fluorescence units (R.F.U.). Data are expressed as percentage of adhesion of bacteria with respect to that in the absence of drug. Increasing amounts of $\alpha \mathrm{mmp}$ or NDs significantly reduce the binding of bacteria to cells. Experiments were performed in triplicate at least 4 times. Statistical analyses and $\mathrm{IC}_{50 \text { s }}$ determination were performed with GraphPad Prism software (GraphPad Inc.). 
A

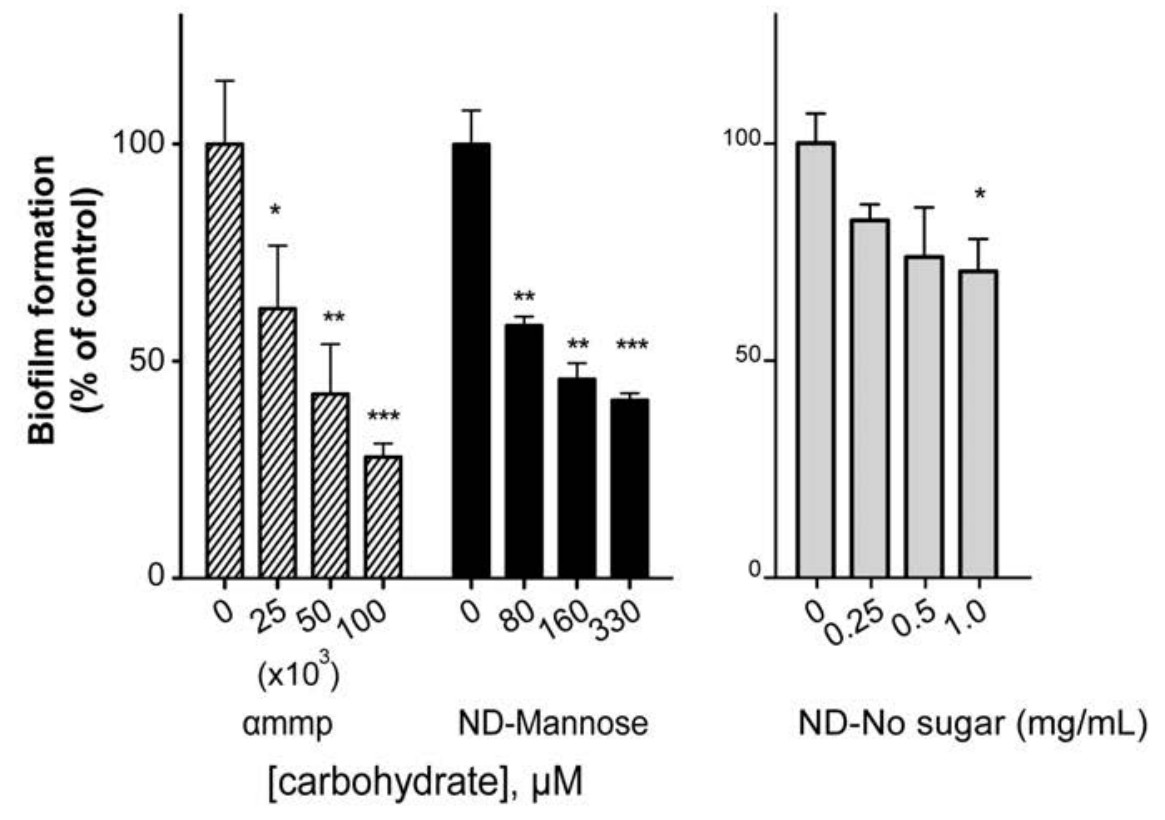

B

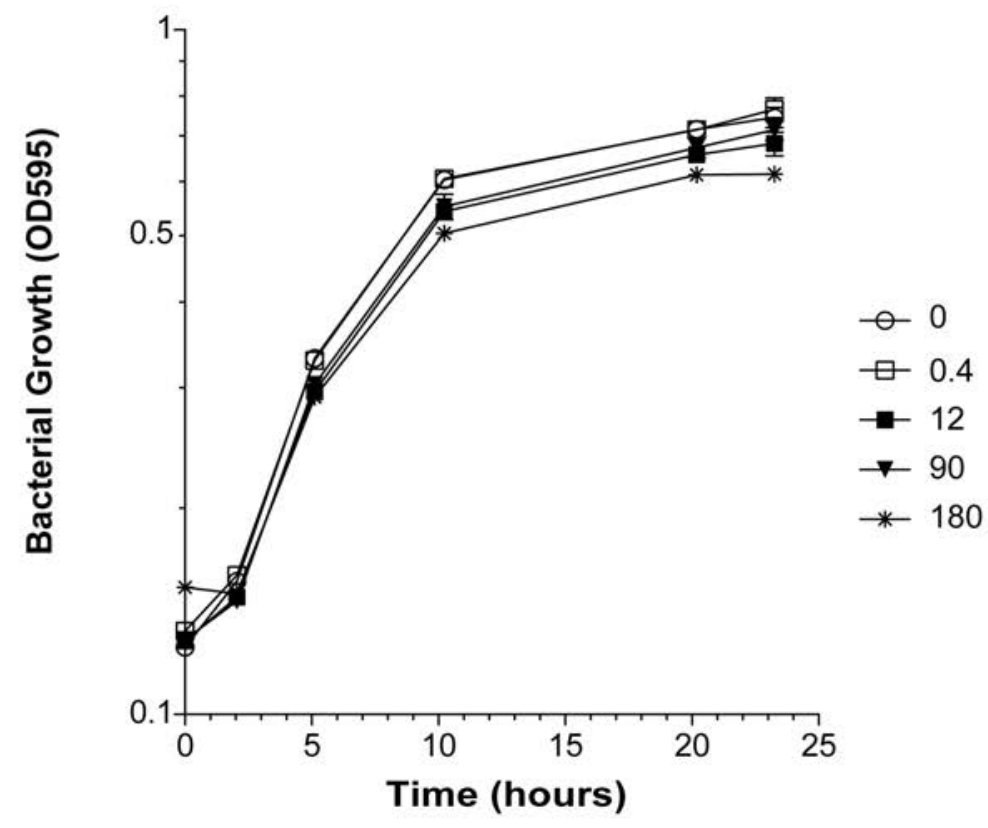

Figure 6. Inhibitory effects of methyl- $\alpha-\mathrm{D}-$ mannopyranoside and NDs on biofilm formation. A) The various compounds were individually added at the start of biofilm growth within microtiter plates. After $24 \mathrm{~h}$ of growth, biofilm formation was evaluated using crystal violet staining. The biofilm formation of type 1 fimbriated strain was reduced in the presence of ammp and ND-Mannose while no or reduced inhibition was observed in the presence of NDNo Sugar. Data is expressed as percentage of growth in the absence of drug. Bars represents mean $\pm \mathrm{SD}, \mathrm{n}=3 . * \mathrm{p}<0.05, * * \mathrm{p}<0.01, * * * \mathrm{p}<0.001$. B) E. coli expressing type I fimbriae was grown in the absence of or in the presence of increasing ND-Mannose concentration 
(ranging from 0.4 to $180 \mu \mathrm{M}$ ) at $37^{\circ} \mathrm{C}$ in M63B1-Gluc media. As shown, there is only a minor decrease in the growth after 24 hours in the presence of $180 \mu \mathrm{M}$ of ND-Mannose. No decrease in growth had been observed after 5 hours or in the presence of lower ND-Mannose concentration after 24 hours. Experiments were performed in triplicate at least twice in a Tecan Sunrise ${ }^{\mathrm{TM}}$ multiwell plate reader. 


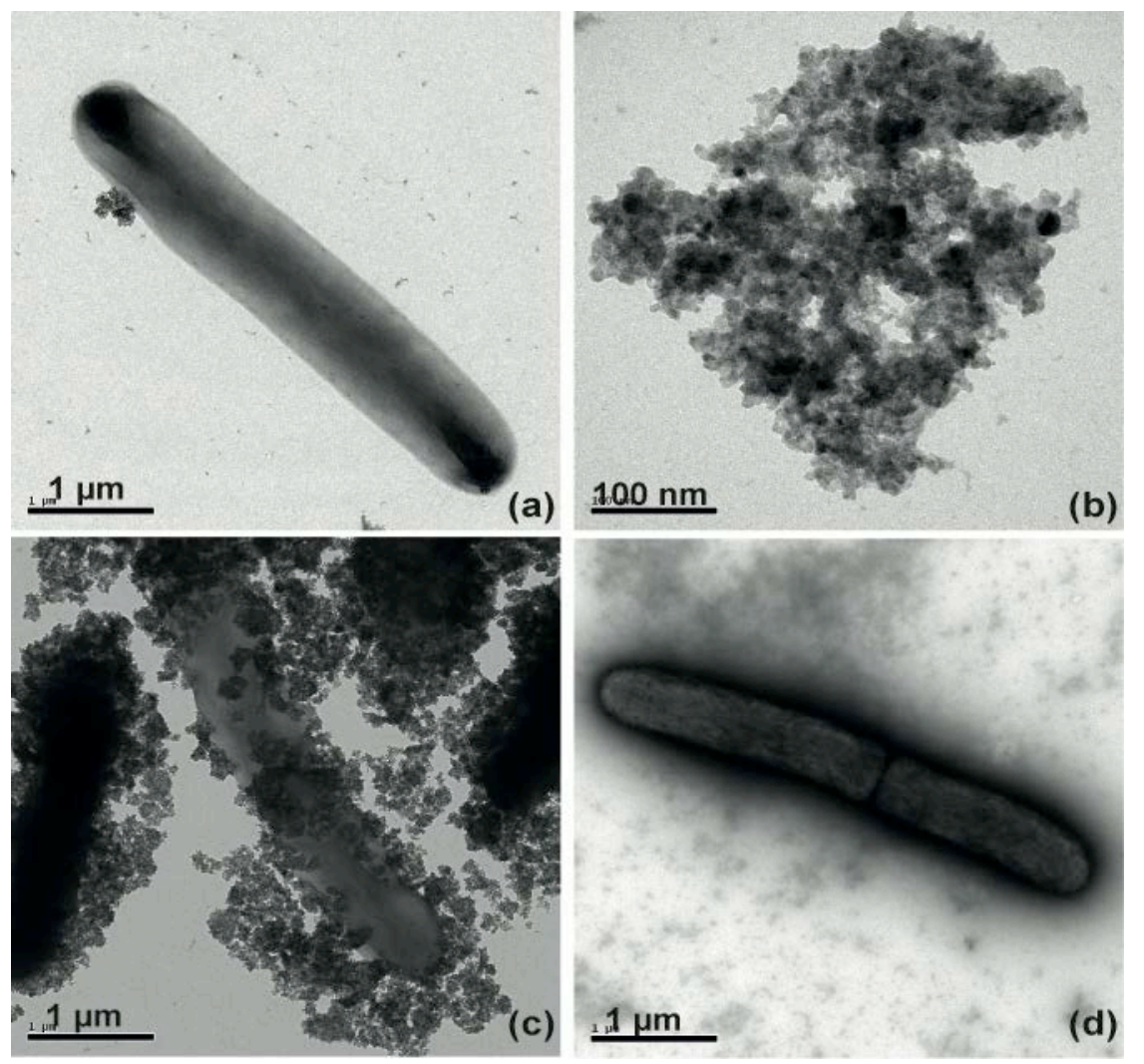

Figure 7. Electron microscopy of glyco-nanodiamonds with either fimbriated and or nonfimbriated E. coli. Cells were incubated during $40 \mathrm{~min}$ in PBS in the presence of different NDs and cells were washed twice in PBS and re-suspended in TRUMP buffer for fixation and transmission electron microscopy observation. Images clearly show an increase in the adhesion of ND-Mannose to cell surface wherein type 1 fimbriae are present. (a) Fimbriated bacteria in presence of ND-Galactose. (b) Images of ND-Mannose alone. (c) Fimbriated cells with ND-Mannose. (d) Non-fimbriated E. coli cells with ND-Mannose. In each panel, NDs were used at a final concentration of $10 \mu \mathrm{g} / \mathrm{mL}$ (3.6 $\mu \mathrm{M}$ carbohydrate). 


\section{SUPPLEMENTARY MATERIALS}

\section{Glycan-functionalized diamond nanoparticles: exceptional inhibition of $E$. coli}

\section{type 1 fimbriae-mediated adhesion}

Alexandre Barras, ${ }^{\mathrm{a}, \#}$ Fernando Ariel Martin, ${ }^{\mathrm{b}, \# 1}$ Omprakash Bande, ${ }^{\mathrm{c}, 2}$ Jean-Sébastien

Baumann, ${ }^{\mathrm{c}}$ Jean-Marc Ghigo, ${ }^{\mathrm{b}}$ Rabah Boukherroub, ${ }^{\mathrm{a}}$ Christophe Beloin, ${ }^{\mathrm{b},{ }^{*}}$ Aloysius

Siriwardena, ${ }^{\mathrm{c}, *}$ Sabine Szuneritsa, ${ }^{\mathrm{a},}$

${ }^{a}$ Institut de Recherche Interdisciplinaire (IRI, USR CNRS 3078), Université Lille 1, Parc de

la Haute Borne, 50 Avenue de Halley, BP 70478, 59658 Villeneuve d'Ascq, France.

${ }^{b}$ Institut Pasteur, Unité de Génétique des Biofilms, 25 rue du Dr. Roux, 75724 Paris cedex 15, France.

${ }^{c}$ Laboratoire des Glucides (FRE 3517 CNRS), Université de Picardie Jules Vernes, 33 rue saint Leu, 80039 Amiens, France.

\# equivalent contribution

1 present address: INSERM U1001, Université Paris Descartes, Faculté de Médecine Necker, 156 rue de Vaugirard 75015 Paris, France

2 present address: Rega Institute for Medical Research, Laboratory for Medicinal Chemistry,

Minderbroedersstraat 10, B-3000 Leuven, Belgium

" to whom correspondence should be sent: cbeloin@pasteur.fr; aloysius.siriwardena@u-picardie.fr;

Sabine.Szunerits@iri.univ-lille1.fr 

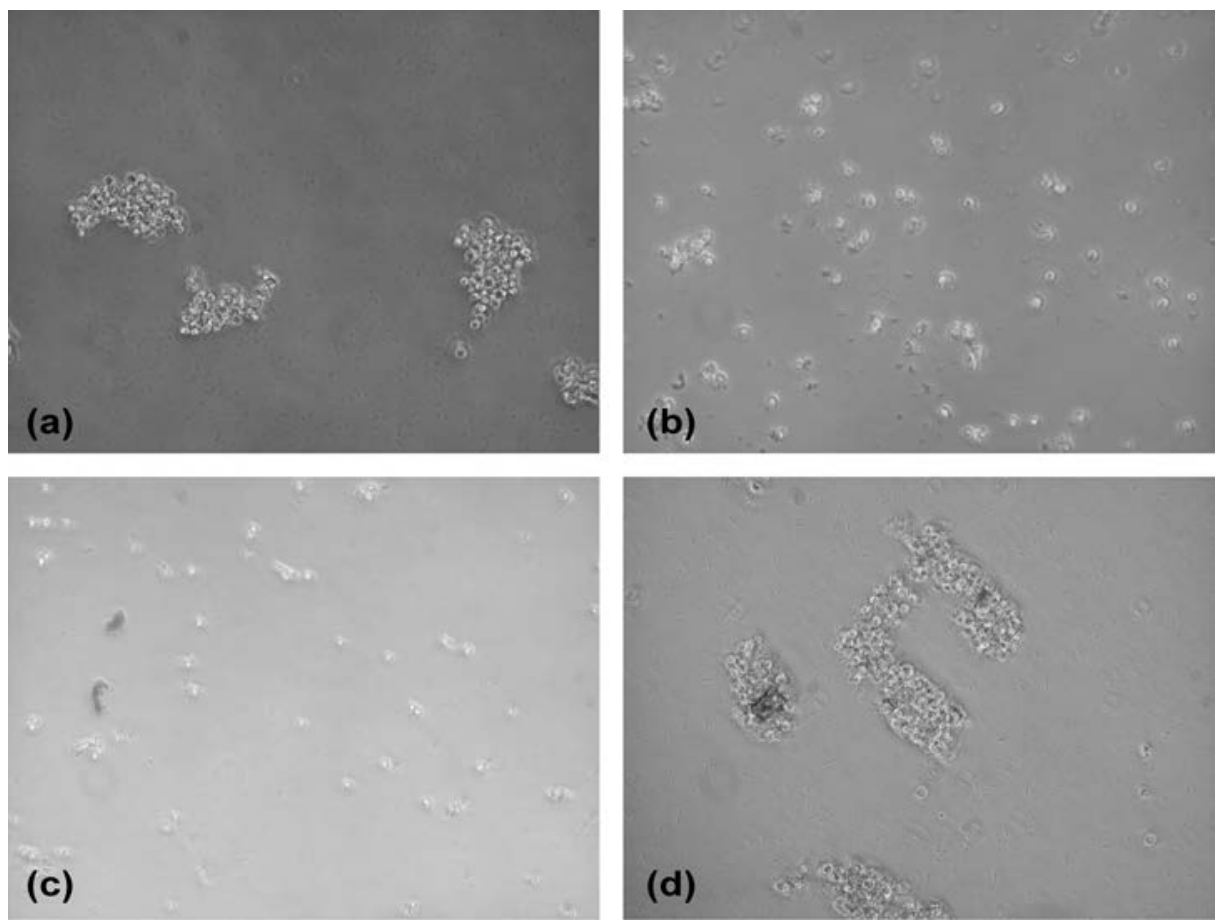

Figure S1. Representative optical microscopy images of yeast agglutination assay in the absence or presence of the inhibitors. Bacteria expressing type 1 fimbriae were grown under static conditions, washed and incubated with (a) PBS; (b) methyl- $\alpha$-Dmannopyranoside, $\alpha \mathrm{mmp}$ (7 mM); (c) ND-Mannose $\left(19.4 \mu \mathrm{g} \cdot \mathrm{mL}^{-1}, 6.8 \mu \mathrm{M}\right)$; (d) ND-No sugar $\left(500 \mu \mathrm{g} \cdot \mathrm{mL}^{-1}\right)$. Cells were incubated for $5 \mathrm{~min}$ and yeast $\left(1 \mathrm{OD}_{600}\right)$ were added and samples observed under the microscope. The experiments were performed in triplicate and at least on three independent occasions experiments. 